\title{
LA FIGURA DEL HERMANO MAYOR EN LA LITERATURA MAGREBÍ DE EXPRESIÓN FRANCESA: PRIMERA SUBVERSIÓN FRACASADA DEL STATU QUO
}

Violeta $M^{a}$ Baena Gallé Universidad de Sevilla

\begin{abstract}
The figure of the elder brother, or even a mentor lacking family bonds, is often found in French-language Maghrebian literature as the initiator of a series of unsuccessful attempts to break up with the established order. This essay will deal with the processes which underlie the question. The corpus of our analysis will consist of three novels: La Statue de Sel (1953), by Tunisian Albert Memmi, Le Passé Simple (1954), by Moroccan Driss Chraibi and La Répudiation (1969), by Rachid Boudjedra of Algeria.

Following the study of these three works, we try to confirm the evident evolution in the role of the elder brother and how this process is influenced by the presence of an archetypical abominal father. Bissor, Camel and Zahir, the respective elder brothers or mentors in the three novels, appear to be the mediators between their younger brothers or protected youths (who actually carry out the subversion of the Status Quo) and the external world. Gradually these characters degrade and get into a spiral of absolute marginalisation. Zahir is the major example of this, because he epitomizes marginalisation in all levels: homosexuality, alcoholism, Judaism, etc.
\end{abstract}

No cabe duda de que la literatura magrebí de expresión francesa, y en especial la narrativa, supuso en sus orígenes una constante transgresión de los sistemas establecidos tanto en el ámbito de la temática tratada en los textos, como con respecto al lenguaje utilizado y la forma en la que éste era manejado por los distintos autores. Sin entrar en detalles, puesto que estas nociones están exhaustivamente estudiadas y completamente aceptadas por la crítica actual, no podemos dejar de insistir en el carácter transgresor que tuvieron dichas novelas, en especial las de la primera época. Temas como el papel de la mujer, la ruptura con tabúes sexuales y religiosos, el nacimiento del arquetipo del padre abominable, la constante referencia a una modernidad occidental en continuo choque con una tradición islámica profundamente anclada en la mentalidad, etc., son recurrentes en la literatura a la que nos referimos. Por otra parte, el uso del francés como lengua vehicular no hace más que ahondar en estas rupturas ideológicas y sociales. Todo ello lleva a muchos autores a vislumbrar la escritura como una catarsis personal y colectiva, y como única salida a los conflictos existenciales a los que a menudo se enfrentan. Así, en numerosos textos, podemos encontrar a personajes (metonímicos de los propios autores) que simbolizan dicha catarsis y rompen con el orden establecido a todos los niveles (social, ideológico, religioso, familiar, etc.). A pesar de todo, dicha ruptura no es fácil y en 
numerosas ocasiones se ve precedida por otras tentativas fracasadas a manos de la figura del hermano mayor del personaje principal.

Con este estudio pretendemos reflexionar sobre los mecanismos que subyacen en estos casos y sobre la razón de su existencia. Para ello, y dado que el corpus específico de esta literatura es inmenso, nos centraremos en tres obras importantes y representativas de cada uno de los países que conforman el Magreb, ordenadas siguiendo un criterio estrictamente cronológico: La Statue de Sel (1953) del tunecino Albert Memmi, Le Passé Simple (1954) del marroquí Driss Chraibi y La Répudiation (1969) del argelino Rachid Boudjedra. A lo largo de este trabajo, veremos cómo existe una evolución evidente entre las relaciones de los personajes en los tres textos que hemos seleccionado.

Albert Memmi, escritor judeo-tunecino, es considerado ${ }^{1}$ el representante por antonomasia de la literatura tunecina en lengua francesa; sus inquietudes y presencias narrativas están muy acordes con los escritores marroquíes y argelinos de su generación. Su primera obra, La Satue de Sel, aparecida en 1953 y reeditada en 1960 con un prefacio de Albert Camus, supone una profunda ruptura con su medio familiar. Es un relato en el que el autor hace balance de su vida en boca de Alexandre Mordekhaï Benillouche, héroe que se presenta en primera persona y que posee claras connotaciones autobiográficas. El texto, que consta de una breve introducción y de tres secciones narrativas de diversa consistencia ${ }^{2}$, plantea la lucha existencial en la que se debate el personaje para poder reconciliar las influencias culturales de las que resulta un heredero directo. Finalmente, descubre toda una serie de factores que están en el origen de su diferencia y exclusión ${ }^{3}$.

Con esta novela, el autor inicia una fuerte crítica contra todos los elementos de los universos que le rodean y sólo concibe como salida aceptable la reunificación y reconciliación de los mismos. Sin embargo, tras una serie de rupturas dolorosas con Oriente y Occidente, se marcha a Argentina.

En este primer texto, la figura del hermano mayor se está perfilando, razón por la cual está menos exhaustivamente tratada que en las otras dos novelas. Bissor, que no es hermano sino amigo de Alexandre, aunque cumple perfectamente dicha función, constituye el mediador indispensable entre el héroe y el mundo exterior en la época de la adolescencia, característica común a las tres obras que analizamos. Así, en la primera sección titulada "L'impasse", que narra la infancia del personaje principal y supone la descripción de su medio social y círculo familiar, Bissor no está presente. Su ausencia está perfectamente justificada si asumimos la tesis de que su persona es el eslabón necesario entre la adolescencia y la madurez de su amigo, por lo que en el momento de la infancia de éste último, la aparición de Bissor no tienen ninguna relevancia. El segundo apartado, "Alexandre Mordekhaï Benillouche", donde el personaje afirma su personalidad en el período de la adolescencia, la existencia de Bissor es esencial como mediador entre la juventud y esta segunda etapa de formación. Pero esta mediación está concebida, en un principio y desde la primera descripción que de él se hace, sobre la base de su fuerza física; este personaje, debido a su papel, no tiene tanta profundidad ideológica y ontológica como

\footnotetext{
${ }^{1}$ Cfr. J.J. Joubert et alii, Les littératures francophones depuis 1945 (Paris: 1986) 226.
}

\footnotetext{
${ }^{2}$ Para consultar un estudio más exhaustivo sobre la estructuración del texto, podemos remitirnos a V. Baena, "Una nueva lectura de La statue de sel de Albert Memmi" Philologia Hispalensis,vol. XII (1998) 73-88.
}

${ }^{3}$ Cfr. Joubert 1986:227. 
física, hecho que irá cambiando en la literatura, como ejemplificaremos con las dos novelas posteriores:

"Bissor était un solide garçon tout en muscles et gros os, comme un cheval de labour. Par quel miracle naissait, de temps en temps, au sein pourri du ghetto, un robuste gaillard, trapu, compact, et riche d'une santé campagnarde? Une tignasse rousse, abondante, indéfrichable comme une jungle, accentuait son aspect primitif., ${ }^{, 4}$

Bissor pertenece al ámbito de lo personal/familiar, completamente separado del resto dominio de lo intelectual y profesional. Estas dos tendencias no son, en definitiva, más que otra manifestación de la dialéctica entre la tradición y la modernidad, entre Oriente y Occidente, a la que está continuamente sometido el personaje principal ${ }^{5}$.

En el tercer apartado de la novela, "Le monde", centrada en el período de madurez de Alexandre, se narran los primeros contactos con el mundo exterior, como su propio nombre indica, vistos bajo el crisol de una perspectiva universal, alejada ya del entorno familiar de la primera parte. En esta apertura, la ayuda de Bissor se percibe como fundamental. Pero la importancia física ya no es tan relevante como antes y el apoyo se basa en otro tipo de factores. Es el encargado de introducirle en la sexualidad, aunque sea en los prostíbulos que le son tan familiares; en este momento su papel de mediador es incluso explícito en el texto:

"Il fallait un médiateur entre ma solitude sexuelle et les femmes. Je n'eus pas besoin d'une longue énumération; seul Bissor, d'entre les dépucelés, ne me moquerait pas cruellement. Ces certitudes me donnèrent le calme pour un temps et me rendirent même moins pressé." (Memmi 1966:259)

Ante este requerimiento, el amigo no hace más que cumplir con las expectativas que se esperaban de él, adoptando incluso tono de hermano mayor, hecho que corrobora nuestra hipótesis inicial:

“Comme je l'espérais, il ne fit aucune plaisanterie, il prit seulement un ton d'aîné dont je lui fus même reconnaissant." (Memmi 1966:260)

Pero la transición de la infancia-adolescencia al mundo de los adultos ya ha tenido una realización efectiva y la funcionalidad de Bissor en el texto no es operativa. Por esta razón, en el capítulo titulado "Les autres", muere. Y con él desaparecen los últimos lazos de unión de Alexandre con su adolescencia. Este período coincide con el descubrimiento del racismo y del antisemitismo, y de una especie de militancia judía por parte de Alexandre. Bajo esta nueva perspectiva, el personaje no puede evitar sentirse culpable por la muerte de su amigo:

"Bissor est mort; et j'ai sur les bras la mort de Bissor dont je ne sais que faire. Misérable diversion européenne ou mouvement spontané d'une foule aveugle, la recherche des responsabilités ne ressucitera pas Bissor." (Memmi 1966:289-290)

\footnotetext{
${ }^{4}$ A. Memmi, La Statue de Sel (Paris, 1966) 112.

${ }^{5}$ Esta dialéctica queda recogida desde el propio nombre del protagonista. Como él mismo explica (Memmi 1966:107-108), su nombre resume las tres culturas de las que es heredero: "Alexandre" aparece como homenaje a Occidente; "Mordekhaî", diminutivo de Mridakh y sinónimo de pobre, pertenece a la tradición judía; por último, "Benillouche" se extrae del dialecto árabo-beréber.
} 
Tras esta última reflexión, Bissor no vuelve a aparecer en la novela pues, como ya hemos afirmado, su funcionalidad ha terminado. A un nivel interpretativo, podemos asegurar que Alexandre ya ha tomado su decisión y su personalidad está completamente afirmada, por lo que la presencia de su mentor ya no tiene razón de ser. En definitiva, el protagonista ha optado por el rechazo de los dos mundos de los que es heredero directo. Por un lado Oriente, metonimizado en las tradiciones y en lo que él mismo denomina "chaînes mythiques" (Memmi 1966:185); por otra parte, su acercamiento a Occidente también le ha decepcionado, por lo que igualmente rompe con sus influencias, ejemplificadas en el texto por el rechazo definitivo de la burguesía ${ }^{6}$.

Driss Chraibi, autor del segundo texto citado, es considerado a menudo como el precursor de la literatura magrebí en lengua francesa, aunque él piensa que no es más que el resultado de una casualidad histórica:

"Je suis né dans la zone française du temps où le Maroc était adminsitré par l'Espagne dans le Nord et par les Français dans le reste du pays. Si j'étais né dans la zone Nord, j'aurais peutêtre écrit en espagnol."

Su primer texto narrativo, Le Passé Simple, supone un ataque virulento contra los valores tradicionales marroquíes en el momento en el que se necesitaba una cohesión frente al Protectorado ${ }^{8}$, hecho que le valió numerosas críticas de sus coetáneos. La lucha contra el colonialismo y contra el patriarcado tradicional coexiste en una escritura en francés que, según J. Kaye, significaba que los valores culturales europeos "podían usarse para refrenar las brutalidades precoloniales":

would fail to distinguis"Chraibi's linguistic sleight of hand disguises the fact that only by writing in French could he suggest that a Muslim family would fail to distinguish between the veneration due to Allah and the respect due to the head of the family, and thus fail to observe the most fundamental principle of their faith: the inalienably unitary nature of Allah." (J. Kaye 1990:47).

Este texto presenta una visión mítica, deformada por el resentimiento, de una familia musulmana subyugada por la autoridad patriarcal, teocrática e incontestable de un padre a quien el Corán reconoce derecho de vida y de muerte sobre los suyos ${ }^{9}$. La figura de la madre aparece pasiva y aterrorizada, viviendo con el fantasma del repudio; está reducida a la inexistencia y se refugia en un "rêve de suicide"10. Como el padre representa la lengua de la dominación, el narrador o el personaje principal están llamados a ser partidarios de la madre ${ }^{11}$. El narrador, por su parte, aceptando en apariencia las reglas de la vida dictadas por

\footnotetext{
${ }^{6}$ Esta decisión se narra en el capítulo titulado “L’escalier” (Memmi 1966:211-225).

${ }^{7}$ Caño y Rivas, "Littérature du Maghreb: interview à Driss Chraỉbi", Ici et là no 23 (1992) 56.

${ }^{8}$ Cfr. J. Kaye y A. Zoubir, The ambiguous compromise (Language, literature and national identity in Algeria and Morocco) (London, 1990) 45.
}

${ }^{9}$ Cfr. J. Arnaud, La littérature maghrébine de langue française, T.I: Origines et perspectives (Paris:1986) 257.

${ }^{10}$ M.T. Bet, "La littérature maghrébine francophone", Cahier de l'association internationale des études françaises, $\mathrm{n}^{\circ} 44$ (1992) 69.

${ }^{11}$ M. Zahiri, "La figure du père dans le roman marocain”, Présence Francophone n 30 (1987) 107. 
el padre, se refugia en un "rêve de meurtre" (Bet 1992:69). La obra, dividida en cinco capítulos, traza el proceso de rebelión y de emancipación personal de Driss Ferdi, de diecinueve años y segundo hijo de un rico comerciante marroquí. Se educa en la escuela francesa y es consciente del drama provocado por el contacto entre las dos culturas que comparte, la oriental y la occidental. Se inclina por esta última, representada por Francia. Diferentes episodios traumáticos surcan la evolución del personaje principal. Debido a su contenido, esta novela propone un fuerte ataque a temas tan primordiales como son la familia, el padre, la religión musulmana y la infancia violentada ${ }^{12}$, entre otros, por lo que la crítica social que se trasluce a un nivel interpretativo es innegable.

Desde el primer capítulo, "Les éléments de base", aparece la figura de Camel, el hermano mayor, -"inconscient, irresponsable et, en présence du maître, le plus perfectionné des pantins"13 - En esta obra, la existencia de este personaje está esbozada con más nitidez que en el texto anterior; así, Camel representa una primera rebelión contra el arquetipo paterno que no llega a buen término, por lo que, excluido en cierta medida del círculo familiar, se refugia en el alcoholismo y en ambientes marginales ${ }^{14}$.

"Camel, je sais où tu es, laisse les copains, les putains, l'alcool. Six ventres troués de faim t'attendent. Je ne compte pas le Seigneur." (Chraibi 1954:21)

En este apartado es cuando se describe el entorno familiar de Driss. Se puede decir que su universo familiar está compuesto por el padre -le Seigneur-, la madre, Camel y sus otros hermanos, que se ven, en principio, como un todo indivisible y casi inexistente ${ }^{15}$ :

“Mon Dieu! Jusqu'ici ils n’ont pas existé. Les chaussures alignées devant la porte leur appartiennent - et les ventres vides. Ils sont cinq, alignés eux aussi, contre le mur. Ils sont assis par ordre d'âge, formant un trapèze presque parfait. Le plus âgé s'appelle Abd El Krim, dix-sept ans. Le puîné en a neuf: Hamid. Ils ne se grattent pas, n'éternuent pas, ne toussent pas, ne rotent pas, ne pètent pas. Ils sont maigres et craintifs. Ils ont les mains posées bien à plat sur leurs cuisses et respirent à une allure modérée, sans bruit. Leurs yeux sont ternes et leur teint terreux. Ce sont mes frères." (Chraibi 1954:25)

Incluso cuando Driss rememora su infancia y hace referencia a su familia, no se percibe ninguna evolución relevante:

“Rien n'a changé depuis. (...) La famille s'est accrue de cinq membres, mais qu'est cela? Ils ont tété un an, peluré deux ans - le temps strict accordé à la prime enfance - et tout de suite

${ }^{12}$ Cfr. I. Mouzouni, Le roman marocain de langue française (Paris 1987) 35.

${ }^{13}$ D. Chraïbi, Le Passé Simple (Paris, 1954) 36.

${ }^{14}$ El propio narrador admite, al hablar de la madre, el carácter predestinado de la existencia de Camel: "Oui, ma mère était ainsi, faible, soumise, passive. Elle avait enfanté sept fois, à intervalles réguliers, deux ans. Dont un fils qui ne pouvait qu'être ivrogne et moi, qui la jugeais." (Chraïbi 1954:44)

${ }^{15}$ I. Mouzouni (1987:34-69), en el capítulo titulado "Critique de l'ordre social et révolte dans Le Passé Simple", esboza una tipología de los personajes de la novela, en la que Driss tan sólo cuenta con lo que él denomina "doubles négatifs", divididos en dos categorías: los marginados de la sociedad y los hermanos del protagonista, que encarnan la decadencia total. 
après ils ont grandi dans la peur et appris le silence. Comme ce soir, tous les soirs ils sont cinq ombres sur le mur." (Chraibi 1954:36)

La primera percepción que se tiene en el texto de Camel corresponde a una fuerte subversión del orden familiar impuesto por el padre, ya que todos están sentados esperando para tomar la cena tras el ayuno del vigésimo cuarto día del mes de Ramadán, y Camel no ha llegado ${ }^{16}$. Es cierto que este personaje no piensa en la rebelión contra la paternidad, pero el hecho de que esté ebrio durante el mes sagrado, supone una herejía y es una clara actitud sacrílega en el contexto de la autoridad religiosa encarnada por su padre ${ }^{17}$.

Esta reflexión resulta prácticamente obsesiva, puesto que la ausencia de Camel aparece explícitamente reiterada en la novela:

“Camel n'est toujours pas rentré (...). Un quart d'heure après le sacro-saint coup de canon, votre fils aîné est encore dehors. Vous avez là, je pense, matière plus que suffisante à maudire le reste de votre progéniture et à répudier votre épouse. (...) Camel n'est pas à votre droite et le silence pèse. Je n'y peux rien." (Chraïbi 1954:19-20)

" Je le posai [le pain] sur son tapis de prière, à sa droite, là où Camel aurait dû être assis." (Chraibi 1954:33)

Esta ausencia provoca incluso la protesta de Driss ante su padre, actitud que le es reprochada enseguida en una agria conversación que termina cuando el padre le lanza un esputo en la cara (Chraibi 1954:30):

"Alors je décidai d'être anathème.

- Vous m'avez dit d'attendre. Attendre quoi? (...) Attendre Camel ou qui ou quoi? Si vous voulez que j'aille...

- Fils, tu as prononcé le nom de ton frère aîné. Que ce soit la dernière fois.

- Mais j'ai faim, je ne peux plus attendre, ce n'est pas ma faute si Camel..." (Chraibi 1954:27)

Finalmente, Camel, "tête de révolté" (Chraibi 1954:42), llega borracho, situación que Driss sitúa al mismo nivel que su perjurio, puesto que las dos actitudes son claras subversiones del orden establecido. Pero los dos hermanos sufren el correctivo del padre, poco antes de la escena en la que Driss experimenta el deseo de muerte de su progenitor mediante su asesinato con un cuchillo que le ha servido en todo tipo de situaciones. La actitud de los dos hermanos en esta escena es completamente diferente. Mientras que Camel permite que Le Seigneur le castigue físicamente, Driss adopta una actitud activa, aunque de momento sólo sea de pensamiento y no tenga una resolución real. Así pues, es muy significativa la pasividad del hermano mayor frente a la toma de posición consciente del otro hijo:

“Ce couteau avait tout coupé: les feuillets de mes livres, le cou des coqs de l'Aïd Seghir (32 au total), la gorge des moutons de l'Aïd El Kebir (10 au total) et, une fois, à la naissance d'Hamid, le ventre de ma mère. (...) Puis le mis dans ma poche, persuadé qu'il pourrait encore

\footnotetext{
16 “Camel n'est pas encore rentré.” (Chraibi 1954:17)

${ }^{17}$ Cfr. I. Mouzouni (1987:46).
} 
servir, d'autres moutons à égorger, une autre césarienne à opérer - et, un jour parmi les jours créés par Dieu, avec un peu d'adresse, un peu de sang-froid, le lancer vers le Seigneur, quelque part vers le corps du Seigneur, vers sa nuque par exemple, où il se planterait jusqu'au manche, comme une aiguille." (Chraibi 1954:43)

De todas formas, el papel de Camel como iniciador y mediador entre su hermano menor y el mundo exterior queda patente. Gracias a él, por ejemplo, Driss comienza su escolarización a la edad de cuatro años (Chraibi 1954:38).

En el segundo capítulo, titulado "Période de transition", Camel no está presente. También es cierto que la acción no se sitúa en el entorno familiar de Casablanca, sino en Fez, donde Driss ha ido con su madre para visitar a sus tíos. De todas formas, encuentra a Jules César, un conductor del autobús que cubre la línea entre las dos ciudades y que podría ser considerado como el sustituto simbólico de Camel, al faltar éste. La muerte imprevista de Hamid, el hermano menor, hace que Driss y su madre vuelvan a Casablanca.

En "Le réactif", tercer capítulo, donde se narra la verdadera rebelión de Driss, Camel vuelve a aparecer ebrio, durante el velatorio de Hamid. En este caso, y dadas las circunstancias, vuelve a ser suplantado por Jules César:

“J'avais dit à Jules César d'être là. Il est là. Il me fait signe de la main et je lui réponds en hochant la tête." (Chraibi 1954:135)

“- (...) Que fait Camel?

- Ivre mort." (Chraibi 1954:148)

Nos parece significativo y digno de señalar el hecho de que Camel pertenece al ámbito familiar, desde todos los puntos de vista, tanto a un nivel humano (teniendo en cuenta la familia en sí), como bajo una perspectiva del espacio físico (la casa, la ciudad, etc.), de forma que su existencia no tiene razón de ser fuera de este dominio de lo privado. El caso de la muerte de Hamid no es más que una fuerte subversión de este orden familiar, de carácter frágil por otra parte. Esta es la razón de que Camel vuelva a ceder, simbólicamente, el lugar a Jules César ${ }^{18}$.

Tras esta muerte, nada vuelve a cambiar en la descripción que Driss hace de su familia:

"Bien sûr, le trapèze contre le mur ne comporte plus que quatre hachures. Mais elles se sont esparcées en conséquence et le trapèze est là. (...) À la droite du Seigneur, Camel. Ivre, je le sais." (Chraibi 1954:155-156)

Pero la debilidad de Camel, queda explícitamente manifiesta en presencia de su padre, al que no es capaz de enfrentarse, ni aun cuando le Seigneur es el causante de la muerte de Hamid.

\footnotetext{
${ }^{18}$ Todo ello se ve corroborado por la certeza que tiene Driss sobre la actitud de Camel quien, en su estado de embriaguez, no quiere implicarse y prefiere aislarse en su mundo particular: " "Ça va durer longtemps, ce business, doit se demander Camel. Bordel de bordel! Si j'avais su, je serais resté au bordel.»” (Chraỉbi 1954:165). Esta misma frase se repite, casi exactamente, en la página siguiente ("Ça va durer longtemps? Doit se demander Camel. Bordel de bordel! Si j’avais su, je serais resté au bordel.”), hecho que incide en nuestra hipótesis del poco entusiasmo que muestra este personaje por mezclarse en la rebelión iniciada por su hermano Driss.
} 
En el siguiente capítulo, "Le catalyseur", Camel aparece completamente sometido a la voluntad paterna. Sus intervenciones son escasas, y se reducen a hacer lo que el padre le ordena, como cuando se convierte en intérprete entre éste y Joseph Kessel, el examinador de Driss, porque el padre no domina el francés como para mantener una conversación con este profesor ${ }^{19}$.

En el quinto y último capítulo, "Les éléments de synthèse", Camel sólo aparece cuando Driss está en el aeropuerto para irse a Francia y vuelve a cumplir con la función de protector del hermano menor:

"Camel a bourré ma valise de spiritueux.

- Il fait froid en France, m'explique-t-il.

Il ficelle mon portefeuille et l'enfonce dans la poche intérieure de mon veston. Qu'il ferme avec une épingle de nourrice.

- Il y a des gangsters en France, m'explique-t-il." (Chraibi 1954:271)

De todas formas, el texto deja bien claro que la rebelión sólo le está permitida al protagonista, y que éste no puede hacer de hermano mayor con el resto de su familia. Es el padre el que lo decide, en dos momentos cruciales: por un lado, cuando dispone, por puro azar, que su segundo hijo sea el elegido ${ }^{20}$; en segundo lugar, cuando mata a Hamid de una paliza e impide que Driss le abra el camino al mundo ${ }^{21}$. Al matar a su hijo menor, Le Seigneur anula cualquier posibilidad de continuidad de rebeldía, porque Driss ya no puede ni ser el protector ni dirigir a nadie, como Camel hizo con él. Esta acción rompe con toda esperanza de liberación. Por esta razón, le hace responsable tanto del suicidio de su madre como del odio que le tienen el resto de sus hijos:

"Ma tâche consistait simplement à te signifier que tu as été cause de sa mort [la mère]. (...) Cause également que mes enfants me haïssent, auparavant ils ignoraient le sens de la haine, l'instinct même de la haine, maintenant ils me haïssent fort bien." (Chraibi 1954:262)

En este texto se esboza una evolución en la figura que estamos analizando, porque Driss resulta, a su vez, hermano mayor de otra serie de personajes; aunque se le niegue toda operatividad desde el relato, debido a las acciones del padre de familia.

El tercer y último texto que nos hemos propuesto analizar es La Répudiation, del argelino Rachid Boudjedra, aparecido, como ya mencionamos al comienzo de este estudio, en 1969. El relato se inicia con la relación entre el narrador y su amante europea, Céline. Ésta, actuando como una psicoanalista, provoca la confesión de Rachid, el narrador y

\footnotetext{
${ }^{19}$ La escena está descrita entre las páginas 214 y 216 del texto. Pero hasta la página 223, en una conversación que Driss mantiene con su padre, no sabemos que la llamada telefónica la realiza éste y que el intérprete es Camel. "(...) Le «Broufizour», c'était vous? / - C'était nous. Monte / - Je monte. Et l'interprète? / - Camel."

20 “'Pourquoi toi parmi tous mes enfants? Sur lequel j'ai porté mon choix, que j'ai dirigé avec patience et soin et à qui je lègue mon fardeau? (...) Pourquoi toi? Un jour j'ai fermé les yeux, pointé l'index. Un hasard, cet index t'a désigné. Voilà." (Chraïbi 1954:266).

21 “Je pense à Hamid, méningite m'as-tu dit, je veux bien, deux ans de plus et il aurait appris toutes les déclinaisons latines et qui sait? mangé une tablette de chocolat, il comptait sur moi pour lui en offir (...)”. (Chraỉbi 1954: 254).
} 
protagonista. Concebida como una catarsis, la novela tiene como núcleo el repudio de su madre, acto que centra el resto de los recuerdos de su infancia: el matrimonio de su padre Si Zoubir con Zoubida, una niña de tan sólo quince años; la escuela coránica; el alcoholismo y la homosexualidad de su hermano Zahir; el incesto que comete con su madrastra; etc. Todos los personajes del texto sufren este repudio como una agresión y lo superan de una forma u otra. Así, Ma (madre del narrador) representa la víctima a todos los niveles. Los tíos de Rachid se erigen como guardianes del honor familiar y no cesan de vigilar a Ma. Zahir, como ya hemos comentado, se recluye en el alcoholismo y la homosexualidad. Yasmina, su hermana, se vuelve loca durante su matrimonio, regresa al hogar familiar y muere de una fiebre intestinal con veinte años. Finalmente, Leilla, hija ilegítima del padre y de una judía, protagoniza diferentes intentos de suicidio.

La novela, bajo una perspectiva interpretativa, plantea un doble conflicto $^{22}$ que se genera y se complementa por el hecho del repudio. Así, en un nivel ontológico, encontramos que la paternidad alienada y la maternidad negada amparan la "enfance saccagée" 23 de la que el propio autor habla. En segundo lugar, en un plano ideológico, la ruptura con la tradición está simbolizada por la rebelión contra la figura paterna. Este conflicto paralelo conlleva dos soluciones: la de Rachid o la ambigüedad de la locura y de la alucinación; y la de Zahir, la subversión de los tabúes de todo tipo y la inclusión en una dinámica marginal a todos los niveles, que analizaremos a continuación.

Como tendremos ocasión de comprobar, en esta tercera novela la figura del hermano mayor está completamente perfilada y definida. Podríamos decir que recoge las influencias de los relatos anteriores para amplificar su importancia y, sobre todo, el sentido de su rebeldía contra el orden establecido, metonimizado en la figura paterna ${ }^{24}$ como ya sucedía en Le Passé Simple. Al igual que en el texto de Driss Chraïbi, el relato está a cargo del segundo hijo, quien denuncia no sólo su drama personal, sino el drama por el que ha pasado toda su familia, incluido Zahir, su hermano mayor. Asimismo, volvemos a encontrarnos con que es el menor el elegido por el padre, y no el mayor como sería esperar ${ }^{25}$.

El personaje de Zahir, a pesar de ser inteligente y buen estudiante ${ }^{26}$, es mucho más marginal que en las dos novelas anteriores y su rebeldía es más explícita y patente. Este personaje representa, en definitiva, una segunda salida -paralela a la del protagonista- a los

\footnotetext{
${ }^{22}$ Para una lectura más profunda de los niveles interpretativos e ideológicos del texto, remitimos a V. Baena y A. Porras, "Espacio y desmitificación en La Répudiation de Rachid Boudjedra", Creación espacial y narración literaria (Sevilla 2001) 83-89.

${ }^{23}$ R. Boudjedra, La Répudiation (Paris 1969) 201.

${ }^{24}$ En este texto, el papel del padre está tratado de forma menos exhaustiva, incidiendo en la importancia de la definición profundizada del hermano mayor y de su rebeldía. De todas formas, aunque los casos de presencia física no sean tan abundantes como en el texto anterior, su poder, despotismo y autoridad resultan manifiestos; y el repudio no es más que el resultado de todo ello.
}

${ }^{25}$ Podríamos citar el episodio en el que se narra cómo es Rachid (con diez años) y no Zahir quien ocupa el lugar del padre en la alcoba al lado de la madre, tras el repudio. Cfr. R. Boudjedra (1969:49).

${ }^{26}$ Hay numerosas citas en el texto que corroboran esta afirmación, y que hacen más significativa, si cabe, la degradación que sufre; ya que su trayectoria no se puede achacar tanto a causas personales, como a agentes externos, como son la familia, la sociedad, la religión, etc. 
conflictos planteados en el texto. El primer acercamiento a esta figura se centra también, como en el caso de Camel, en el alcoholismo y en el mes del Ramadán, período durante el cual deja de beber en honor a los principios islámicos:

"Te dire que je n'aimais pas le mois de Ramadhan serait mentir. Nous savions guetter la lune. L'attente du mois sacré était bénéfique. Zahir s'arrêtait de boire pendant un mois. Ma reprenait espoir. La maison avait un air de fête" (Boudjedra 1969:19).

El tema del alcoholismo será recurrente en el texto ${ }^{27}$, y muestra una de las facetas del carácter marginal al que nos referimos anteriormente, aunque el autor lo disculpa por la naturaleza tan traumática del hecho del repudio de la madre:

"Mon frère a dix-sept ans et fréquente les bars louches de la ville depuis la répudiation de ma mère. Il boit dans les bars espagnols, italiens et juifs de la ville." (Boudjedra 1969:101)

El alcoholismo se concibe como una alternativa a las prácticas religiosas. Y, al igual que sucedía en el texto de Chraïbi, el hermano menor se siente responsable de la actitud del mayor, de forma que incluso se lo recrimina. Representativas son las escenas similares de las dos novelas en las que tanto Camel como Zahir no regresan a la casa porque están borrachos y el menor (Driss o Rachid, según el caso) se siente preocupado por las consecuencias de este hecho tanto para el propio personaje, como para la familia en general y la madre en particular. En este caso concreto, las funciones de los hermanos se ven alteradas y superpuestas, de manera que es el menor el que cuida del mayor y no viceversa:

"Je trouve que Zahir exagère. Pourquoi se saoule-t-il? Il dit toujours que c'est pour croire en Dieu. Je ne vois pas du tout le rapport. (...) Je lui casserai la gueule, à mon frère, dès qu'il sera rentré. Je profiterai de son état d'ivrogne précoce. Alcoolique! (...) Dois-je descendre et aller à la recherche de Zahir? Mais où le trouver?" (Boudjedra 1969:101-102)

Finalmente, hace tiempo que el hermano está echado en la escalera de la casa sin fuerzas ni ganas de subir:

"Je dégringole les escaliers, décidé à trouver l'ivrogne n'importe où. Mon frère est là, en bas, recroquevillé sur lui-même, la tête posée sur la première marche.

- Je n'ai pas pu monter...

Il pue. Il se tord. Ma devine. Descend. A deux, nous le portons jusque dans son lit." (Boudjedra 1969:102)

La personalidad de Zahir es bastante compleja. Sus momentos de rebeldía se confunden con ataques de locura en los que su reacción se centra en blasfemar y en emprender una dura batalla contra las mujeres, sintiendo una gran repulsa, sobre todo, por la sangre y por las secreciones corporales de éstas ${ }^{28}$. Su rebelión contra la religión y contra el universo

\footnotetext{
27 "Zahir, entre-temps, baguenaudait; ses cils se mouillaient. Ce soir, il se saoulera à mort" (Boudjedra 1969:92); "Il se fait tard et Zahir n'est pas encore rentré. Nous l'attendons. Je prends un air décontracté, mais au fond de moi-même j'ai très peur. Mon frère peut se faire écraser par une voiture car il ne dessaoule pas depuis une semaine." (Boudjedra 1969:99)

${ }^{28}$ En este sentido, hay un pasaje muy significativo que recoge las reflexiones que Zahir ha dejado escritas en un diario, leídas por Rachid tras la muerte de su hermano, en las que intenta explicar su repulsión y ganas de vomitar
} 
femenino es completamente consciente ${ }^{29}$, aun cuando su representación es confusa en los espacios alucinatorios:

"Zahir, de son côté, menait une campagne terrifiante contre elles [les femmes], et nous exposait son plan pour se débarrasser de ce mal mensuel qui les terrassait sans cause apparente; en fait, notre frère aîné était désespéré et acculé à une sorte de cécité mentale." (Boudjedra 1969:25)

Más tarde, refiriéndose a una discusión con su hermana Saïda sobre la utilidad y obligatoriedad de practicar el ayuno durante el mes de Ramadán, confiesa:

“«Lamentable! répétait-il, elle ne comprend pas qu’elle est aussi atteinte que les autres, et son mal est d'autant plus terrible qu'elle ne réagit pas. Ne pas faire le Ramadhan n'est pas une fin en soi, il s'agit de lier un tel acte aux autres actes de révolte.»" (Boudjedra 1969:26)

Y lleva esta rebelión a sus últimas consecuencias: al no poder soportar el, según él, ambiente de hipocresía de los burgueses y grandes comerciantes al ayunar, desaparece durante días, se marcha a Francia, aunque vuelve criticando el fanatismo de aquéllos que regresan al país durante el mes sagrado para observar el ayuno.

Zahir sufre uno de los ataques de locura más violentos en la boda de su padre con Zoubida, durante el cual pretende matar a un feto ${ }^{30}$, presencia obsesiva en el relato:

“Zahir n'apparaissait toujours pas et personne ne s'en inquiétait. Vers la fin de la noce, il rentra complètement saoul et jeta l'émoi parmi les femmes en leur faisant publiquement de l'oeil. (...) Ma dut quitter précipitamment la cuisine pour soigner Zahir, l'aîné de ses enfants, tombé dans un délire homicide: il prétendait vouloir tuer un foeuts, sans donner trop de précisions. (...) Folie de mon frère, de plus en plus délirant.” (Boudjedra 1969:64-65)

En los momentos de lucidez, Zahir le cuenta a su hermano escenas de la familia, le enseña a odiar a su padre ${ }^{31}$ e incluso planean juntos su asesinato, todo ello rodeado con escenas de fuerte transgresión de los principios sagrados y religiosos:

cuando ve o huele la sangre menstrual femenina. (Boudjedra 1969:104-105.) Asimismo, Zahir le traslada a Rachid el odio por la sangre y, consecuentemente, por lo que ella representa. (Boudjedra 1969:194).

29 "L'atmosphère de fête se diluait peu à peu dans une tension infernale, en raison de la suspicion que l'aîné de Ma cultivait volontairement: «Tu sens le sang et le carême, toi!»" (Boudjedra 1969:25).

${ }^{30}$ Este feto será objeto de numerosas referencias del narrador. Del texto no se deduce su significación exacta, aunque provoca una cierta desazón en el hermano mayor. De todas formas, el misterio que lo rodea no se verá resuelto ni siquiera tras la muerte de éste: “(...) Zahir était mort sans être parvenu à éclaircir l'énigme du foetus (...)" (Boudjedra 1969:151). Véanse las citas siguientes como ejemplos de la presencia obsesiva que provoca el feto en el hermano mayor: "Ma cessa de s'occuper de Zahir qui continuait à garder rancune au foetus dont l'énigme restait complète aux yeux de tous" (Boudjedra 1969:72); "Zahir, revenu à son courage, clamait cette foisci contre le foetus des menaces terrifiantes;" (Boudjedra 1969:88); y el misterio del feto queda sin resolver: "(...) nous continuons à tout ignorer du foetus, chose amorphe et sans consistance. Zahir, persécuté par nos questions pertinentes, prenait des airs surnois; au fond il était dépassé par son propre mythe. Il ne savait rien du foetus ni de sa constitution mais ne voulait pas le reconnaître. (...) Personne ne savait donc ce que c'était qu'un foetus; le dictionnaire, comme dans la plupart des cas, restait vague, très vague. Nous en étions écoeurés; que voulait donc tuer Zahir?" (Boudjedra 1969:89)

31 “(Ne pas hésiter: les buter, lui, sa gamine et le foetus, répétait-il.)” (Boudjedra 1969:68). 
“Zahir haissaï la tribu et pissait dans l'eau qui servait à l'ablution des saints hommes et des lecteurs du Coran.” (Boudjedra 1969:68-69)

Tras la boda de su padre, en la que Zahir no deja de repetir que Zoubida está enamorada de él ${ }^{32}$, éste sufre una transformación física y adopta aires de rabino, haciendo que la situación familiar sea cada vez más insostenible. Se encierra en un silencio "fatal" (Boudjedra 1969:72) y sólo sale de este trance para narrarle a las mujeres el mundo exterior que les está vetado y describirles la ciudad en la que muchas de ellas han nacido y que no conocen en absoluto. Se puede afirmar que la ciudad, como espacio exterior, le pertenece, mientras que Rachid sigue encerrado en el espacio interior, femenino, representado por la casa familiar. Y, por supuesto, será Zahir el que lo incite a salir de ese ámbito para iniciar al protagonista en las experiencias sexuales en los prostíbulos de la ciudad y quien lo introduzca en los ambientes marginales que el exterior ofrece, cumpliendo con la función de hermano mayor que ya hemos analizado en los textos anteriores. Existen varias referencias a los paseos que dan ambos, pasajes en los que queda nítidamente especificado el papel de mediador de Zahir:

"J'aime, avec mon frère aîné, me glisser au sein de cette humanité malencontreusement vivante. (...) Zahir m'expliquait beaucoup de choses, mais je ne comprenais que confusément et il ne me restait qu'une poignante certitude, que le sang rendait morose." (Boudjedra 1969:59)

En todo este contexto, las relaciones paterno-filiales se deterioran progresivamente, como era de esperar, y Zahir hace frente a su padre ${ }^{33}$, hasta tal punto que hay un intento de parricidio fallido, en el que el enigma del feto sigue presente, y donde la imagen del cuchillo recuerda al mismo pasaje vivido por Driss en Le Passé Simple :

“"Ј'étais décidé à tuer le père... J'ai été à la villa, mais je n'ai pas pu accomplir mon acte car Zoubida dormait dans le grand lit avec Si Zoubir et le foetus dormait dans Zoubida. Je n'ai pas pu... J'ai même été emprunter son couteau au vieil Amar.»

Por último, otro de los factores que nos hacen pensar en la transgresión del orden establecido es la homosexualidad de Zahir, explícitamente tratada en el relato:

“Zahir, lui, n'aimait pas les femmes. Il était amoureux de son professeur de physique, un juif aux yeux très bleus et très myopes qui venait souvent à la maison, malgré l'hostilité marquée de ma mère." (Boudjedra 1969:103)

Poco a poco, esta homosexualidad se va desvelando ${ }^{34}$ hasta que, incluso, se detalla una escena en la que Zahir mantiene una relación con un joven del vecindario que es

${ }^{32}$ Esta misma afirmación la realiza el narrador, una vez ya consumado el acto de incesto con su madrastra: "M'acceptait-elle [Zoubida] par commodité? Certainement, car elle ne cachait pas son admiration pour Zahir qui lui vouait une haine meurtrière." (Boudjedra 1969:126).

${ }^{33}$ Tras la muerte de Zahir, Rachid confiesa que el odio entre los dos era mutuo: "Le père, transfiguré de joie, dansait autour de l'éternel coffre-fort; il haïssait son fils aîné depuis la répudiation dont personne ne s'était jamais remis" (Boudjedra 1969:152).

34 "Dès que le marchand m'adresse la parole, je me crispe. Homosexualité latente. Tout le monde sait qu'il a des rapports maléfiques avec mon frère." (Boudjedra 1969:107). 
fortuitamente presenciada por su madre y por sus hermanos sin que él se percate de esta circunstancia. Ante tal situación, la madre no sabe cómo reaccionar y lo explica como "un jeu brutal" (Boudjedra 1969:212). Dicha escena es rememorada por Rachid cuando un cliente del horno al que ha llevado un cordero, le obliga a hacerle tocamientos obscenos. Pero la homosexualidad es un tema tabú y no confesable ${ }^{35}$ en esa sociedad anclada en las tradiciones ${ }^{36}$.

La situación se deteriora cada vez más, de forma que Zahir ya llega todas las noches borracho a la casa y desaparece largos períodos de tiempo en viajes misteriosos ${ }^{37}$. En cierto episodio, en el que se confunde la realidad con las alucinaciones de Rachid, parece que éste acompaña a Zahir a una clínica (Boudjedra 1969:125-126) en la que se curan los casos de alcoholismo, aunque la situación no queda nítidamente reflejada en el texto, debido a una intención clara del autor de que no se pueda reconstruir exactamente la historia narrada. Finalmente, Zahir, al igual que Bissor de La Statue de Sel, muere. Pero esta muerte será mucho más significativa y tendrá más trascendencia que la del personaje analizado en el texto de Memmi. En primer lugar, el lector es consciente de esta realidad por una prolepsis del narrador ${ }^{38}$.

Poco después, esta indefinición queda corroborada ${ }^{39}$ y da lugar al episodio de la narración del traslado del cadáver del hermano desde Francia, acompañado por el padre ${ }^{40}$,

35 "Je me lance dans le vide (...), enfant pourchassé (...), déchiqueté déjà par les futurs sarcasmes des tantes et des voisines, miné par le silence qu'il faudra observer pour ne pas déranger les certitudes d'une société ancrée dans ses mythes de pureté et d'abstinence. Comment dénoncer l'ignoble personnage que tout le monde a vu, le matin même, en train d'égrener son chapelet et de sacrifier son mouton? Il faut se taire; seul Zahir pourrait expliquer l'épisode du four." (Boudjedra 1969:210).

${ }^{36}$ A pesar de la crítica que el autor hace de la hipocresía de la sociedad, disculpa esta práctica en el caso de las proposiciones homosexuales que realiza el maestro en la escuela coránica. Defiende que el "taleb" se ve obligado a ello a causa de la pobreza, reiterando una vez más el rechazo a las costumbres ancestrales y las tradiciones esclerosadas de una sociedad, en cierto sentido, enferma: "Tout le monde accepte les propositions du maître coranique! Il nous caresse furtivement les cuisses et quelque chose de dur nous brûle le coccyx. C'est tout! (...) Les parents, généralement au courant de telles pratiques, ferment les yeux pour ne pas mettre en accusation un homme qui porte en son sein la parole de Dieu; (...) Ma soeur dit que c'est là une séquelle de l'âge d'or arabe. Plus tard, j'ai compris que c'est la pauvreté qui incite le «taleb» à l'homosexualité, car dans notre ville il faut avoir beaucoup d'argent pour se marier. Les femmes se vendent sur la place publique, enchaînées aux vaches, et les bordels sont inaccessibles aux petites bourses!" (Boudjedra 1969:94-95).

${ }^{37}$ (Boudjedra 1969:115, 118, 124,etc).

38 “(Mais pourquoi parler de Zahir? n'était-il pas mort?)” (Boudjedra 1969:130)

39 “Zahir est mort depuis une éternité déjà." (Boudjedra 1969:135). A pesar de ello, e incidiendo en la confusión entre los momentos reales y los alucinatorios, Rachid vuelve a cuestionarse esta muerte: "Zahir était-il réellement mort?" (Boudjedra 1969:178), hasta que, finalmente, esta muerte es confirmada en el propio relato (Boudjedra 1969:240).

${ }^{40}$ A pesar de que es Si Zoubir quien acompaña al féretro, las relaciones entre los dos no habían mejorado, y el autor insiste en dejar este hecho explícitamente recogido en el relato: "Zahir n'avait jamais eu de père et ce n'était pas en se travestissant en cadavre nauséabond à la décomposition avancée qu'il allait en avoir un; le gros commerçant exultait bruyamment et ne cachait pas sa joie d'être venu à bout du fils lapidaire qu'il avait toujours craint plus que n'importe qui." (Boudjedra 1969:153). 
en el que encontramos una definición un tanto amarga de Zahir ${ }^{41}$ y donde se concibe esta muerte como la conclusión lógica de la situación mantenida y sostenida por todos ${ }^{42}$ :

"La mort de mon frère n'était que la conséquence normale des actes du clan qui se préparait déjà à une vengeance longtemps attendue; Zahir n'était que la victime expiatoire d'une violence obligatoire qui allait se déverser sur la contrée et n'épargner personne; l'alcool, comme le sang, était nécessaire à la terre exondée et bouleversée pendant un long répit insupportable." (Boudjedra 1969:152-153)

Hay un intento de reivindicación de la figura deteriorada de Zahir al fundirlo en la misma escena con los elementos naturales del sol y del mar, en una especie de comunión perfecta, en el episodio en el que se narra el momento en el que el féretro es bajado del barco por una grúa que se avería y lo mantiene en suspensión entre el mar y la tierra (Boudjedra 1969:162 y ss.). De todas formas, esta imagen positiva es anulada en seguida, cuando la grúa deja en tierra el "fardeau pestilentiel" (Boudjedra 1969:163) del hermano. El trayecto entre el puerto y la casa materna está repleto de elementos que vuelven a incidir en el deterioro al que aludíamos anteriormente, como es el olor del cadáver, la actitud de los acompañantes y plañideras, el calor sofocante, etc., de forma que, finalmente, la imagen de Zahir permanece con el grado de marginalidad y descomposición que había ostentado en vida.

Tras el análisis exhaustivo que hemos llevado a cabo de la figura del hermano mayor y/o mentor en los tres textos propuestos, y al realizar una comparación entre ellos, hemos podido llegar a una serie de conclusiones muy significativas. Bissor, el primero, no era exactamente hermano de sangre de Alexandre, pero funciona como tal ${ }^{43}$; se incide en su fuerza física y cuando su papel de mediador entre Alexandre y el mundo finaliza, pierde su funcionalidad y muere. En definitiva, actúa como una especie de mentor del protagonista. En este texto no aparece el padre como arquetipo abominable y Bissor no mantiene una dialéctica con él.

Camel, hermano de Driss ${ }^{44}$ en Le Passé Simple, goza de un tratamiento mayor por parte del autor. Se perfilan ya los ambientes marginales y Camel bebe, aunque su subversión radica esencialmente en este hecho. El papel de mediador entre el menor y el mundo es más explícito y, aunque el arquetipo del padre abominable ${ }^{45}$, núcleo generador del universo

41 "(...) insanités d'un ivrogne, (...) un homosexuel invétéré, adorateur de juifs et fumeur de kif, mort dans une ville
étrangère, loin de la terre ravagée et de la tribu peu incline à des tractations aussi louches;" (Boudjedra 1969:152).

${ }^{42}$ El narrador hace una especie de inventario en el que deja patente quienes se alegran por esta muerte (entre los que se encuentran el padre y los tíos) y a qué personajes les ha conmocionado (la madre, la madrastra, Heimatlos el amante judío-, el propio Rachid, etc.) (Boudjedra 1969:152-153).

${ }^{43}$ En realidad la no-existencia de lazos de consanguinidad se debe a que la novela no se centra en la crítica del orden familiar, como sí lo harán los dos textos posteriores, sino en la descripción del proceso evolutivo y de las crisis personales del protagonista.

${ }^{44}$ En este caso, así como en La Répudiation, las relaciones entre los personajes sí son de sangre, puesto que los autores dirigen sus críticas, entre otras cosas, contra el contexto del sistema familiar.

${ }^{45}$ Hablamos de autoridad paterna con respecto a los hijos en el objeto que nos ocupa, pero como muy bien señala I. Mouzouni (Cfr.Mouzouni 1987:54 y ss.), en el caso de las mujeres, este paternalismo del padre es sustituido por el del marido, siendo la amalgama entre la autoridad del marido, la superioridad y la dependencia a la tutela de 
simbólico del texto y "père castrateur et infanticide" (Mouzouni 1987:49), está perfectamente definido, mantiene cierta relación con su progenitor. Su rebelión contra el orden establecido fracasa desde el momento en el que no es capaz de superar la autoridad paterna, pero su funcionalidad no termina al marcharse Driss, por lo que no muere. Este personaje comenzó su lucha personal contra el sistema, pero en un momento determinado su padre se impone y su batalla fracasa. La única huella y reminiscencia que permanece de esta subversión en el presente de la narración es el hecho de que Camel ya no sea el predilecto, como correspondería a su condición de primogénito. Por eso el padre se ve obligado a buscar un sustituto y es cuando elige a Driss, tal y como se demuestra en el episodio que ya hemos comentado anteriormente ${ }^{46}$.

De todas formas, y proponiendo una lectura del nivel ideológico del texto, podemos afirmar que las relaciones entre el padre y sus hijos, sobre todo Driss, simbolizan el conflicto de generaciones: padre contra hijos, Protectorado contra nacionalismo ${ }^{47}$, etc...

Por último, Zahir, el personaje más castigado de los tres, entra en una dinámica marginal tras el repudio que domina y condiciona todos los actos de su vida. El odio contra el padre es perfectamente patente y su fracaso es rotundo, sin posibilidad de reincidir, por lo que muere en Francia, excluido del ambiente familiar, con toda la carga de resentimiento y de humillación que supone el traslado de su cadáver. Si Zoubir, pues, le sobrevive, siendo este hecho significante de la victoria sobre la rebelión de su hijo.

En los tres casos, estos personajes constituyen los mediadores entre los espacios familiares (interiores y, en su mayoría, feminizados) y los espacios sociales (exteriores y masculinizados). Siendo el paso entre unos y otros significante de la madurez de la persona, los hermanos mayores no han sido capaces de superar esta transición de una manera satisfactoria, de forma que hablamos de fracaso de sus trayectorias existenciales. Y, siendo conscientes de ello, ayudan a sus respectivos hermanos a que realicen esta iniciación sin problemas.

Como podemos comprobar, esta figura sufre un proceso evolutivo por el que su existencia se va haciendo cada vez más marginal y cruda, transmitiendo el pesimismo de las rebeliones fracasadas que deben ser retomadas por los hijos segundos, con un grado de consecución que varía en cada caso. El máximo exponente de esta degradación estaría en Zahir, que representa la marginalidad a todos los niveles: homosexualidad, alcoholismo, judaísmo, etc. Por citar un ejemplo de las distintas opciones a las que se ven obligados los hermanos menores, Driss se marcha a Francia pensando que allí encontrará lo que busca y blasfemando con todo lo que deja en su casa, mientras que Rachid se ve abocado a la salida de la locura.

Realmente, no en toda la literatura magrebí encontramos esta figura tan degradada, aunque su carácter secundario es evidente en la mayoría de los casos. Como muestra de esta última idea, podríamos aludir a otro texto de Driss Chraïbi, La civilistation, ma mère!..., en el que la visión de Nagib, el hermano mayor del narrador de la primera parte y supuesto

éste, lo que lleva a la concepción de la mujer, no ya como una niña, sino como un ser verdaderamente inferior. Este hecho sería una de las causas que estarían en el trasfondo del suicido de la madre de Driss, por ejemplo.

${ }^{46}$ Cfr. Nota ${ }^{\circ} 20$.

${ }^{47}$ Cfr. J. Arnaud (1986:260). 
protagonista ${ }^{48}$, es mucho más dulce. En clave de humor, el lector asiste a la proyección del papel de $\mathrm{Nagib}^{49}$ de mentor del hermano hacia la propia madre, figura que, por cierto, está más valorizada y dignificada que en las novelas anteriores. Bajo otra perspectiva completamente diferente, Mouloud, hermano mayor de Faïza en La Chrysalide de Aïcha Lemsine, mantiene una trayectoria que, si bien no se puede considerar como un fracaso en la ruptura del orden establecido, no es menos cierto que el papel de mentor de su hermana posibilita que ésta sea capaz de romper con tradiciones y costumbres ancestrales, hecho mucho más significativo que la evolución de Mouloud, si tenemos en cuenta que estamos ante un personaje femenino.

\section{BIBLIOGRAFÍA DE REFERENCIA}

J. ARNAUD, La littérature maghrébine de langue française, T.I: Origines et perspectives (Paris 1986).

V. BAENA, "Una nueva lectura de La statue de sel de Albert Memmi", Philologia Hispalensis Vol.XII (1998) 73-88.

V. BAENA, "La función nominativa del lenguaje en La civilisation, ma mère!... de Driss Chraibi", Actas del II Coloquio sobre los estudios de Filología Francesa en la Universidad Española (1993) 87-93

V. BAENA y A. PORRAS, "Espacio y desmitificación en La Répudiation de Rachid Boudjedra", Creación espacial y narración literaria (Sevilla 2001) 83-89.

M.T. BET, "La littérature maghrébine francophone" Cahier de l'association internationale des études françaises $n^{\circ} 44$ (1992) 69.

Ch. BONN, N. KHADDA, A. MDARHRI-ALAOUI, (Ouvrage collectif, sous la direction de), La littérature maghrébine de langue française (Paris 1996).

R. BOUDJEDRA, La Répudiation (Paris 1969).

CAÑO Y RIVAS,: "Littérature du Maghreb: interview à Driss Chraibi" Ici et là $\mathrm{n}^{0} 23$ (1992) 56.

D. CHRAÏBI, Le Passé Simple (Paris 1954).

D. CHRAÏBI, La civilisation, ma mère!... (Paris 1972)

M. GONTARD, Violence du texte (Paris 1981).

J.J. JOUBERT ET ALII, Les littératures francophones depuis 1945 (Paris, 1986).

J. KAYE y A. ZOUBIR, The ambiguos compromise (Language, literature and national identity in Algeria and Morocco) (London 1990).

A. LEMSINE, La Chrysalide (Paris 1995)

A. MEMMI, La Statue de Sel (Paris 1966).

I. MOUZOUNi, Le roman marocain de langue française (Paris 1987).

M. E. PEÑALVA, "Espacio de la Naturaleza, espacio de liberación en La civilisation, ma mère!... de Driss Chraibi”, Voix de la Francophonie (Barcelona 1999) 413-423.

\footnotetext{
${ }^{48}$ Para consultar una lectura más profunda sobre este texto en particular, remitimos a V. Baena, "La función nominativa del lenguaje en La civilisation, ma mère!... de Driss Chraibi", Actas del II Coloquio sobre los estudios de Filología Francesa en la Universidad Española (1993) 87-93, y M. E. Peñalva, "Espacio de la Naturaleza, espacio de liberación en La civilisation, ma mère!... de Driss Chraỉbi”, Voix de la Francophonie (1999) 413-423.

${ }^{49} \mathrm{Al}$ igual que en el caso de Bissor, el autor incide en la fuerza física de este personaje.
} 
M. ZAHIRI, "La figure du père dans le roman marocain", Présence Francophone $\mathrm{n}^{\circ} 30$ (1987) 107. 
